Goldschmidt 2021 Abstract

https://doi.org/10.7185/gold2021.5716

\section{Direct imaging of diagenetic fluid penetration into benthic foraminifera tests}

DEYANIRA CISNEROS-LAZARO ${ }^{1}$, ARTHUR ADAMS ${ }^{2}$, JINMING GUO ${ }^{1}$, SYLVAIN BERNARD ${ }^{3}$, DAMIEN DAVAL ${ }^{4}$, ALAIN BARONNET ${ }^{5}$, OLIVIER GRAUBY ${ }^{5}$, TORSTEN

VENNEMANN $^{6}$, STOLARSKI JAREK ${ }^{7}$, STÉPHANE ESCRIG $^{1}$, LUKAS P. BAUMGARTNER ${ }^{6}$ AND ANDERS MEIBOM $^{1,6}$

${ }^{1}$ École polytechnique fédérale de Lausanne

${ }^{2} \mathrm{EPFL}$

${ }^{3}$ IMPMC CNRS/Sorbonne Université/MNHN

${ }^{4}$ University of Strasbourg

${ }^{5} \mathrm{CINaM}$

${ }^{6}$ University of Lausanne

${ }^{7}$ Polish Academy of Sciences

Presenting Author: Deyanira.cisneroslazaro@epfl.ch

The oxygen isotope ratio of fossil calcitic foraminifera tests has been extensively used as a proxy for the oceanic deep-water and sea-surface temperatures covering the last 140 million years. However, the accuracy of these records is challenged by the process of diagenesis, which recent experimental work shows can modify the bulk isotopic composition of foraminifera tests without observable textural changes $[1,2]$. Understanding how foraminifera tests equilibrate with pore fluids in sediments after burial is therefore a vital step towards identifying and correcting for bias due to diagenesis in paleoenvironmental reconstructions.

Results are presented of experiments designed to simulate the effects of fluid-mediated diagenesis by exposing calcitic tests of three modern foraminifera (Ammonia sp., Haynesina germanica and Amphistegina lessonii) to ${ }^{18} \mathrm{O}$-enriched artificial seawater in chemical equilibrium with calcite at $90{ }^{\circ} \mathrm{C}$ for 4 hours or 6 days. Fluid pathways are identified and isotopic exchange of the foraminifera tests is quantified using NanoSIMS imaging, scanning electron microscopy (SEM), transmission electron microscopy (TEM), and bulk isotope measurements. After simulated diagenesis treatment, the foraminifera tests were texturally indistinguishable from unreacted foraminifera under high-resolution SEM imaging, yet NanoSIMS imaging and bulk isotope measurements revealed heterogenous but pervasive isotopic exchange with the fluid. Correlation of high ${ }^{18} \mathrm{O}$ enrichment patterns from NanoSIMS imaging with SEM and TEM images revealed that organic-rich ultrastructures, common to all foraminifera, create a network for efficient water penetration and subsequent isotopic exchange. The speciesspecific spatial distribution of ultrastructures correlates with the bulk isotopic enrichment, indicating species-specific diagenetic susceptibility.

These experiments demonstrate that the complex ultrastructures of foraminiferal tests permit rapid and pervasive water penetration and isotopic exchange with porewaters during diagenesis. This finding can be extrapolated to many other marine biogenic calcites and demonstrates the importance of ultrastructural characterization in modelling the effects of diagenesis.

[1] Bernard, S., Daval, D., Ackerer, P., Pont, S. and Meibom, A. (2017) Nature Communications 8, 1-10.

[2] Chanda, P., Gorski, C. A., Oakes, R. L. and Fantle, M. S. (2019) Earth and Planetary Science Letters 506, 428-440. 